\title{
Improvement in Accuracy of Heat Load Calculation for Irregularly used Rooms
}

\author{
Yuki Ebihara ${ }^{1}$, Tatsuo Nagai ${ }^{1}$ \\ ${ }^{1}$ Tokyo University of Science, Tokyo, Japan
}

\begin{abstract}
Currently, typical air-conditioning schedules used in facility design often assume certain fixed durations of continuous operation; however, these are not applicable to rooms that are not regularly used, such as meeting rooms. Owing to this, there might be discrepancies in the selected capacity of an airconditioning unit and the calculated primary energy consumption of the building.

In this study, we performed a Monte Carlo simulation, which stochastically decided the operation time of air conditioners based on the state transition probability of room occupancy. Further, using this model, we investigated the effect of irregular room usage on the heat load calculation.
\end{abstract}

\section{Introduction}

Currently, in the heat load calculations of multiple rooms of similar room usage, all the rooms are assumed to be routinely occupied. However, this assumption is not valid when there are rooms that are not used on a regular schedule. Owing to this, the current calculation methods may project that the use of a split individual air-conditioning system, which works only when the rooms are occupied, will result in a design inappropriate for the actual usage conditions. Methods for selecting the capacity of a device based on simultaneous usage rates have been proposed in the past, and these have already been implemented in the field of plumbing. Therefore, we believe that it is possible to use the stochastic usage rate of air conditioning to select the air-conditioning unit of appropriate capacity.

J.Page et al.(2008) simulated the typical behavior of occupants using a Markov chain. Further, K.U. Ahn et al.(2016) investigated three approaches to reproduce the state of room occupancy: the stochastic, agent, and random walk approaches. However, they did not investigate the effect of occupancy on the heat load calculations.

In their research, J.Tanimoto et al. (2009) created a stochastic behavior model by studying the daily activities of occupants. With the collected data, they performed a Monte Carlo simulation and calculated the heat load; however, the considered room types were limited to those found in a residence. Further, they subdivided the collected data based on the attributes of the residents and their behavioral patterns with respect to the day of the week to reproduce the behaviors. However, such a behavioral model is difficult to create since a massive amount of data needs to be collected.

Thus, in this study, we collected data only on the occupancy of the rooms, i.e., on the presence or absence of occupants, to compute the state transition probabilities. Using the obtained state transition probabilities, we reproduced the airconditioning usage in randomly used rooms using a Monte Carlo simulation and investigated the effect of irregular room usage on the heat load calculations of office buildings.

First, we studied the air-conditioning start time and duration of operation, and investigated the deviation in the actual conditions from a typical airconditioning schedule.

Next, we created a model that stochastically determines the occupancy of a room. The presence or absence of occupants cannot be measured directly; therefore, a field study was conducted during midsummer to collect the data, and the start/stop of the air conditioner were respectively assumed to be equivalent to the presence/absence of occupants in a room. The presence/absence of room occupants was thus determined based on airconditioning start/stop data.

We performed a Monte Carlo simulation using the obtained state transition probabilities, and tabulated the maximum heat load, air-conditioner operation time, and cumulative period heat load in the summer. By comparing the resulting heat loads with those obtained by applying the conventional fixed air-conditioning schedules and the measured actual air-conditioning schedules, we investigated methods to improve the accuracy of heat load calculations of randomly used rooms.

\section{Field study of air-conditioning operation}

In this study, we used the hourly energy consumption information of indoor air-conditioning units obtained from a heat load database, which were measured from individual split air-conditioning systems that were not 
centrally managed. Regardless of the energy consumption per hour, i.e., even if the air conditioner operated only for a short duration in an hour, it was assumed functional in that hour. To correlate the use of air-conditioning to the occupancy of a room, we chose a study period in midsummer (July, August), when it is safe to assume that an occupant would certainly use the air conditioner while in the room. The information on the properties considered for this study is listed in Table 1.

Table 1: Property information

\begin{tabular}{|c|c|c|}
\hline Property Use & Hotel & Office \\
\hline Room us age & Guest room & Conference room \\
\hline Number of buildings & 9 & 5 \\
\hline Number of rooms & 90 & 16 \\
\hline
\end{tabular}

Figure 1 is a time-series graph illustrating the use of air conditioners in 10 rooms of a property. Figure .2 shows the average start time of the air conditioners in the hotel guest rooms. Figure .3 illustrates the frequency distribution of the average air-conditioning duration in the hotel guest rooms. Figure .1 indicates that the operation of air conditioners in the hotel guest rooms is irregular. The air-conditioning units do not all start at the same time, and the duration of usage is also irregular. From Figure 2, it can be observed that the air-conditioning units are frequently turned on in the evening, when guests start to check in and immediately after they wake up in the morning. We can see from Figure 3 that short operation times have the highest frequency; long operation times have a lower frequency. This may be due to a direct relationship between the start/stop of the air conditioner and the behavior of hotel guests.

As per the energy conservation standards used in $\mathrm{Japan}^{3)}$, the air conditioners in hotel guest rooms are assumed to be continuously used from 7 PM to 10 AM. Under this assumption, because there are no long periods without air conditioning, the extreme variations in the room temperature are not considered. Consequently, the calculated start-up load of the air conditioner will not be very large. This implies that the calculated design capacity of indoor units by this method may be underestimated. Additionally, there is a possibility that the design capacity of the outdoor units may be overestimated to account for the start-up load of all the rooms at the same time, if we assume that all the indoor units will start at the same time. Consequently, the heat load calculated using the conventional fixed schedule used for the design might result in a deviation from the actual values. Thus, to increase the accuracy of the heat load calculation of rooms that are not regularly used, we created a model, which stochastically determines the occupancy status of a room.

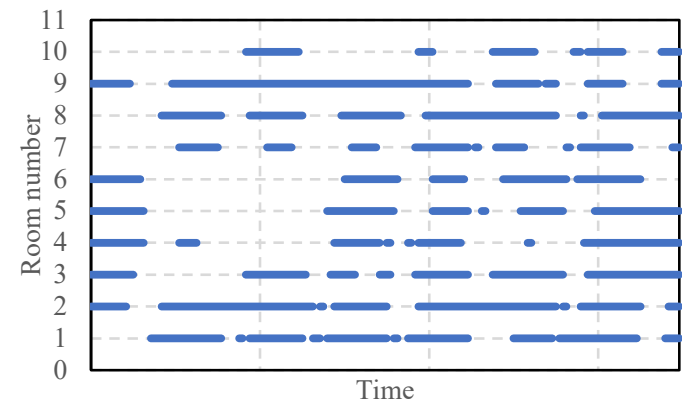

Figure 1: Time series graph of the start/stop of air conditioning at a property (Hotel - Guest room)

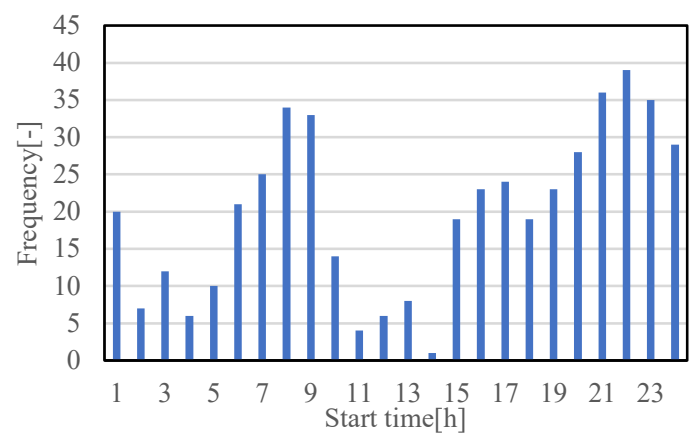

Figure 2: Frequency distribution of average airconditioning start time (Hotel - Guest room)

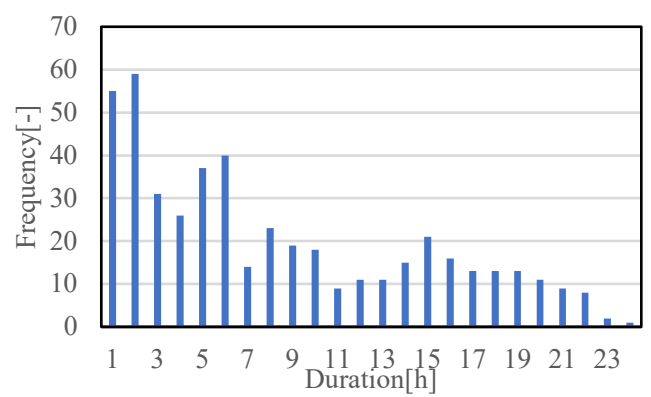

Figure 3: Frequency distribution of average airconditioning duration (Hotel - Guest room)

\section{Proposed usage model}

We created two state transition probabilities to represent the presence or absence of occupants for the room types under study. The "Unoccupied $\rightarrow$ Occupied" state transition probability is the probability that a room will go from being out of use to being in use, and the "Occupied $\rightarrow$ Unoccupied" state transition probability is the probability of the reverse situation. Further, we categorized these probabilities by the days of the week, i.e., weekday, Saturday, and Sunday, and by the hour (for 24 hours). For this, the empirical data related to the occupancy of rooms at each time point are required. Since we were unable to get this data directly, we conducted afield study to acquire the data during midsummer, when we could safely assume that the occupants would definitely turn on the air conditioning while in a room. We used the energy consumption of the indoor unit and the operation time to determine the room occupancy.

We then performed a Monte Carlo simulation using the conditions shown in the flow chart of Figure 
4 to stochastically determine the on/off condition of the air conditioner. Uniform random numbers were used to determine whether a state transition probability was satisfied. If a room is established as occupied, the heat load is calculated from the air conditioning and ventilation usage; otherwise, if a room is established as unoccupied, natural room temperature calculations are performed.

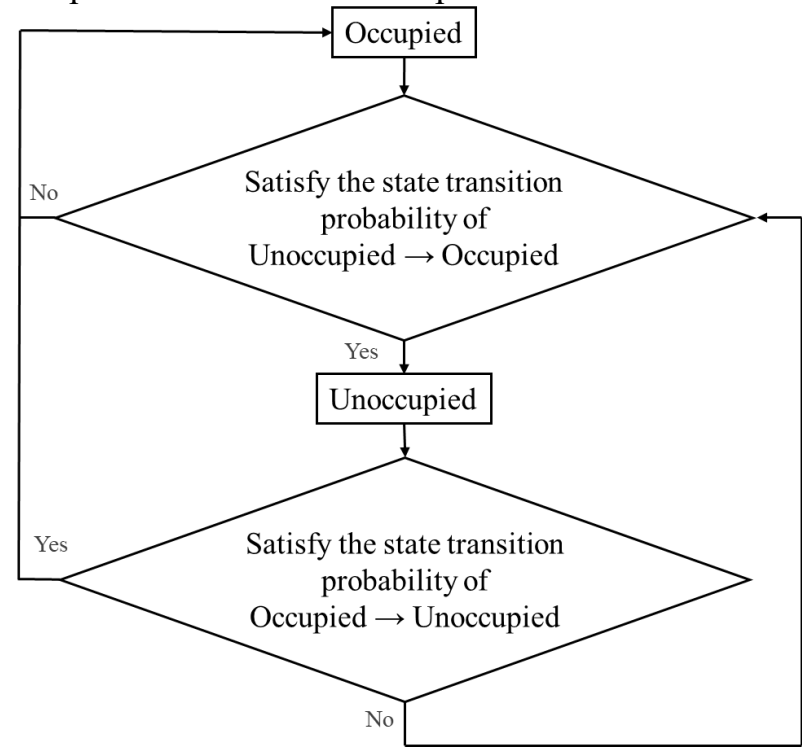

Figure 4: Air conditioning start/stop flow chart

\section{Example 1 (Hotel - Guest room)}

In this example, the peak heat load and cumulative period heat load of a hotel room were calculated, and the effect of the uncertainty of occupancy on the heat load was investigated.

Figure 5 shows the Unoccupied $\rightarrow$ Occupied state transition probability, and Figure 6 shows the Occupied $\rightarrow$ Unoccupied state transition probability for a hotel guest room. These graphs were plotted based on the data obtained from the 90 rooms in the 9 buildings under study, as shown in Table 1. It was observed that theUnoccupied $\rightarrow$ Occupied state transition probability was higher around the wake-up time and check-in time of guests, and the Occupied $\rightarrow$ Unoccupiedstate transition probability was higher during the day.

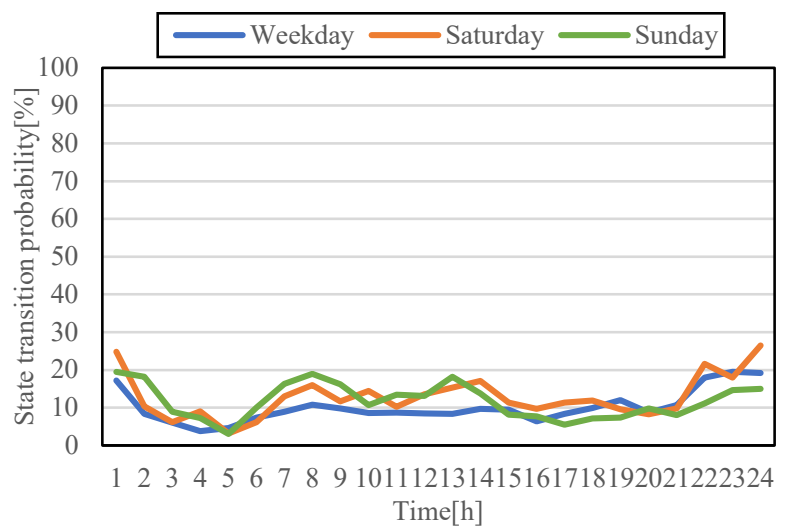

Figure 5: Unoccupied $\rightarrow$ Occupied state transition probability (Hotel - Guest room)

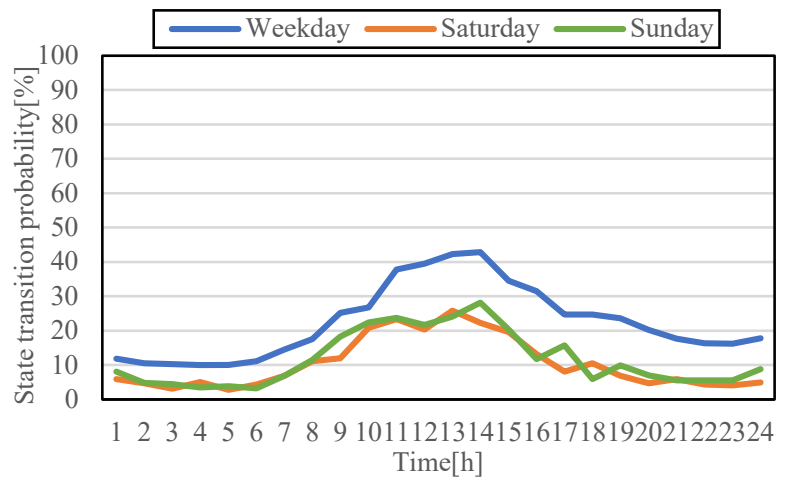

Figure 6: Occupied $\rightarrow$ Unoccupied state transition probability (Hotel - Guest room)

Figure 7 shows the plan of the theoretical standard hotel guest room; this plan remains continuous for every 10 rooms. All the typical design items except the air-conditioning start/stop were used for all the test conditions. Table 2 lists the calculation conditions, and Table 3 shows the composition of the outer wall.

In Case 1, the actual air-conditioning start/stop times of all the 90 rooms were used as the schedule for the calculations. In Case 2, the conventional fixed schedule was adopted for one room. For the airconditioning start and stop times, the average values were calculated for the studied properties; they were calculated to be from $7 \mathrm{PM}$ until 9 AM the next morning. In Case 3, the schedule of 10 rooms obtained from the model that uses the state transition probabilities of occupancy were used for the calculations. The accuracy of a case was determined by how close its results are to those of Case 1 . 


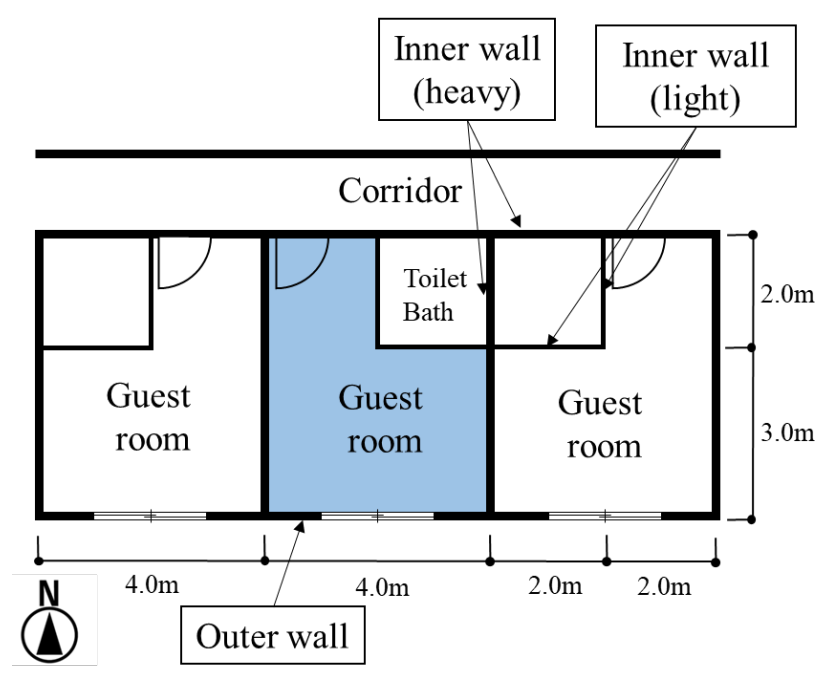

Figure 7: Floor plan (Hotel - Guest room)

Table 2: Calculation conditions(Hotel - Guest room)

\begin{tabular}{|c|c|}
\hline Calculation condition & Input data \\
\hline Location & Tokyo $(35.68 \mathrm{~N}, 139.7 \mathrm{E})$ \\
\hline Temperature & $26^{\circ} \mathrm{C}$ \\
\hline Humidity & $50 \%$ \\
\hline Lighting heat generation & $15.0 \mathrm{~W} / \mathrm{m}^{2}$ \\
\hline Human body heat generation & $6.4 \mathrm{~W} / \mathrm{m}^{2}$ \\
\hline Equipment heat generation & $4.0 \mathrm{~W} / \mathrm{m}^{2}$ \\
\hline
\end{tabular}

Table 3: Wall composition - Outer wall

\begin{tabular}{|c|c|}
\hline \multicolumn{2}{|c|}{ Indoor } \\
\hline Gypsum board & $8 \mathrm{~mm}$ \\
\hline Unseald hollow layer & - \\
\hline polystyrene form & $25 \mathrm{~mm}$ \\
\hline Concreat & $150 \mathrm{~mm}$ \\
\hline mortar & $25 \mathrm{~mm}$ \\
\hline tile & $10 \mathrm{~mm}$ \\
\hline \multicolumn{2}{|c|}{ Outdoor } \\
\hline
\end{tabular}

Figure 8 compares the time series graphs of airconditioning loads. Here, the load of the outdoor unit is calculated as the sum of the loads of the indoor units at each time interval. We know that a longer idle period of the indoor unit will result in a heavier startup load. Because the indoor units are started at different times, sharp peaks are not observed in the outdoor unit.

Next, we compared the loads of the indoor units. Figure 9 shows that in Case 1 and Case 3, the air conditioning starts/stops irregularly, resulting in heavy loads. Conversely, in Case 2, the air conditioning starts/stops regularly; therefore, no extreme peaks are observed in the load.

From Figure 10, we can observe that the airconditioning duration has a considerable variation in Case1. This might largely be related to the degree of prosperity and disposition of guests. The airconditioning operation in Case 2 is regular; since the room temperature does not rise extremely, the heat load does not become unnaturally high. In Case 3, the operation of the air conditioner is irregular, which results in intermittent high heat loads; the durations of air conditioning are also close to the mean of the actual conditions. Meanwhile, in Case 3, a Monte Carlo simulation was performed using a 10-room model, in which there were no variations between the rooms. Figure 11 shows that in Case 2, the peak load was underestimated by roughly $60 \%$. In Case 3 , high accuracy was observed for the estimation of small values of peak loads. Additionally, it was observed that during the study period, the maximum heat load decreased when the duration of operation increased, except in Case 2. Figure 12 shows that in Case 2, the cumulative period heat load and operation time tends to be overestimated, while the results obtained from Case 3 were close to those obtained from Case 1 . 

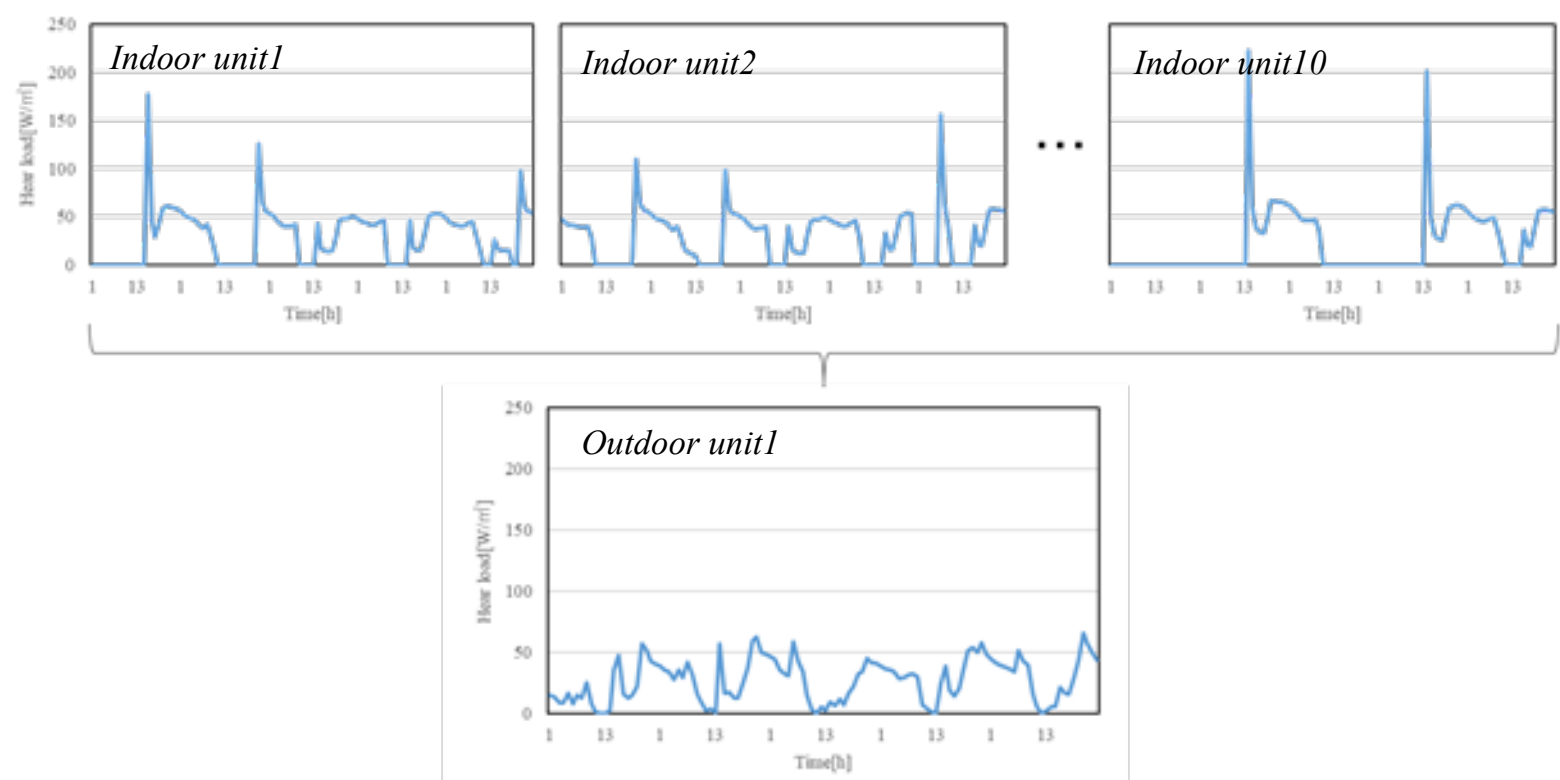

Figure 8: Time series graph of indoor and outdoor units at a property from August 1 to August 5 (Hotel - Guest room)
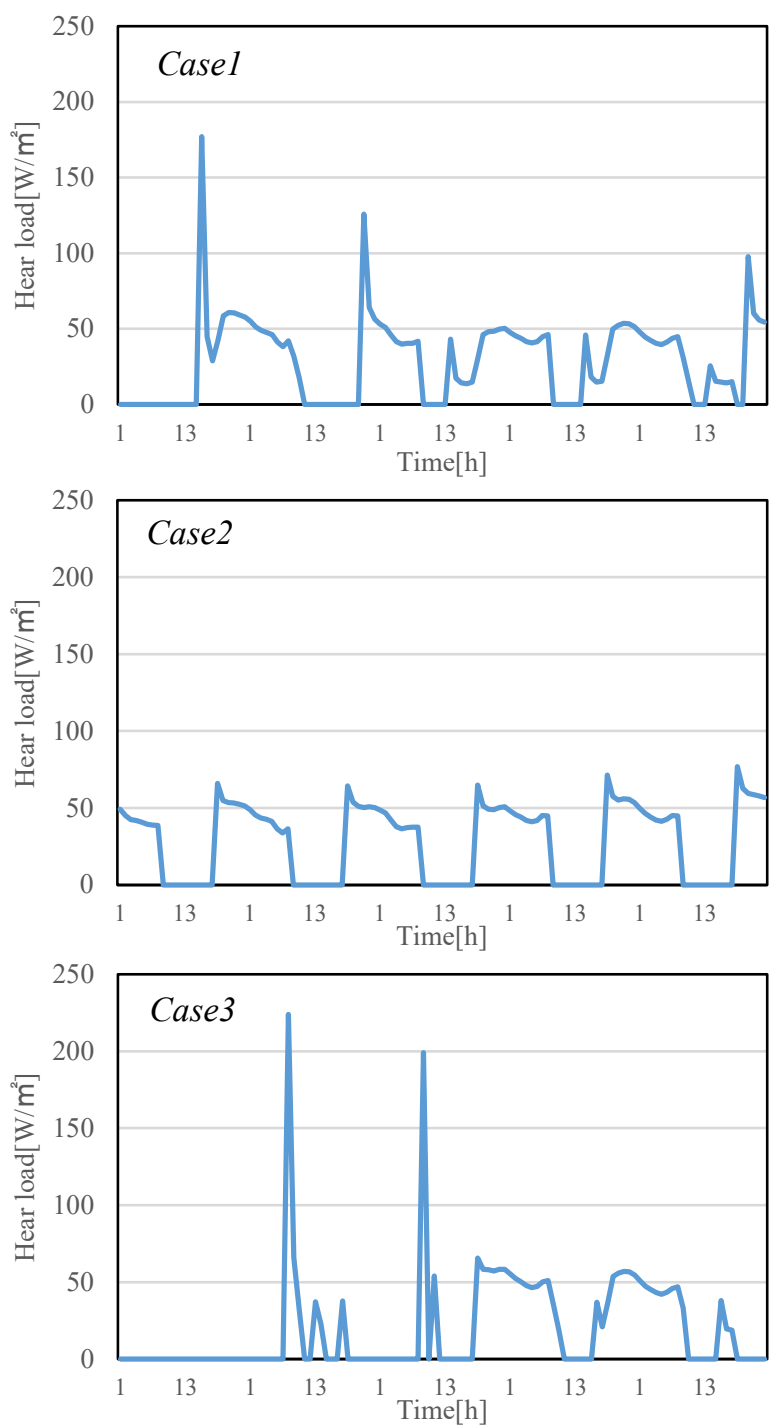

Figure 9: Time series graphs of indoor units in each case(Hotel-Guest room)

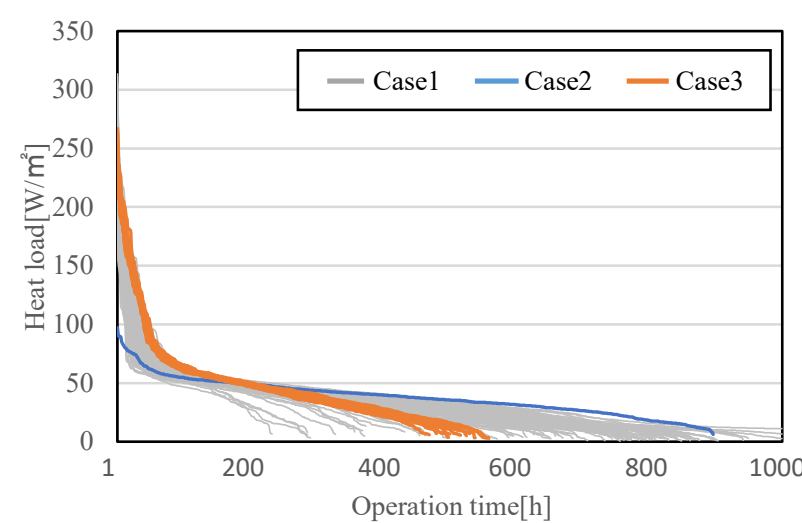

Figure 10: Indoor unit duration curve (Hotel-Guest room)

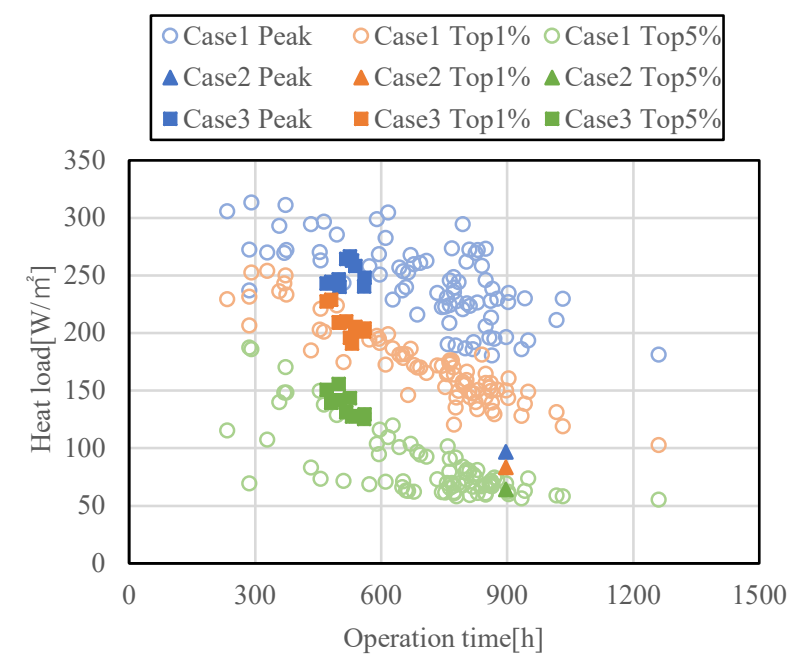

Figure 11: Indoor unit operation time and peak heat load

(Hotel-Guest room) 


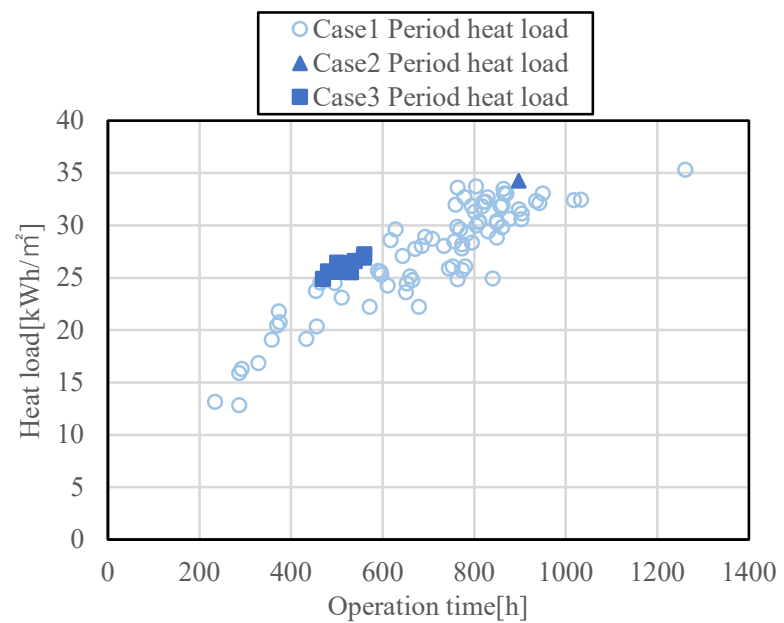

Figure 12: Indoor unit operation time and cumulative period heat load (Hotel - Guest room)

Next, we compared the results obtained for the outdoor units. From the duration curves shown in Figure 13, it was observed that the operation time of the outdoor units is short in Case 2 since all the indoor units operated at the same time. The duration obtained in Case 3 was observed to be more precise. This might be because the start times of the air conditioners are not concentrated at a particular time and the outdoor unit load is leveled out because the start/stop of the air-conditioning units is irregular as in Case 1. Figure 14 shows that the peak load in Case 2 is slightly overestimated and the results of Case 3 are more accurate. Figure 15 shows that the operation time is short in Case 2; however, since the load on the indoor unit is higher cumulatively, we can observe that the results are overestimated.

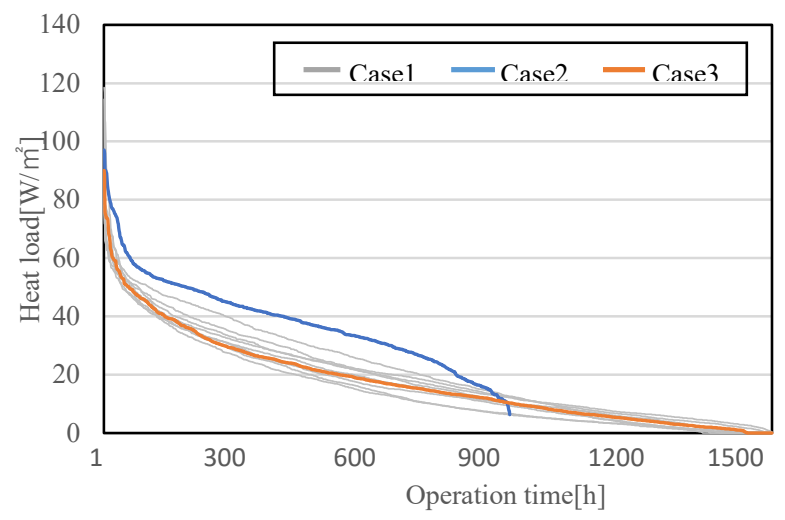

Figure 13: Outdoor unit duration curve (Hotel-Guest room)

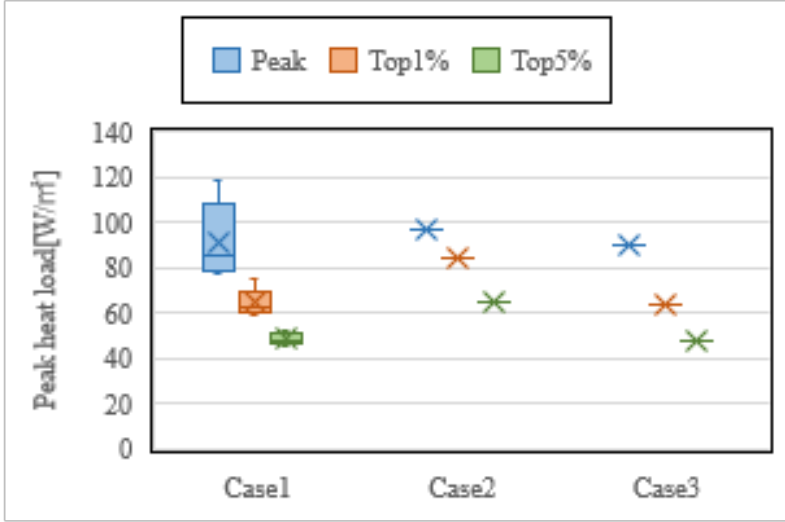

Figure 14: Outdoor unit peak heat load (Hotel-Guest room)

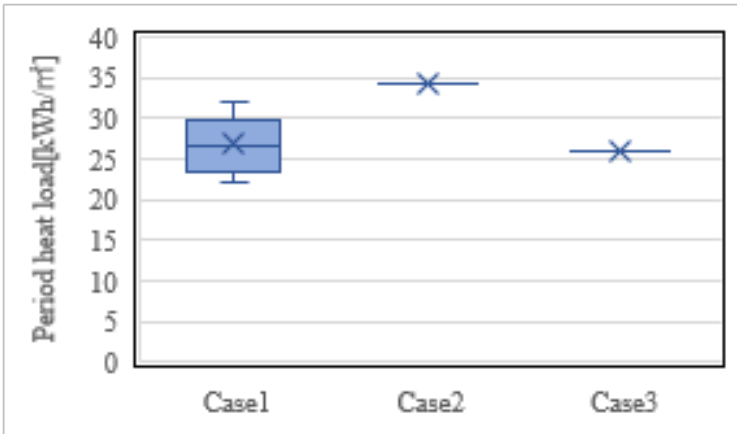

Figure 15: Outdoor unit cumulative period heat load

(Hotel-Guest room)

\section{Example 2 (Office - Conference room)}

Similar to the investigations conducted on the heat load of hotel guest rooms, we also investigated the effect of irregularity in occupancy of conference rooms in office buildings.

Figure 16 shows the Unoccupied $\rightarrow$ Occupied state transition probability, and Figure 17 shows the Occupied $\rightarrow$ Unoccupied state transition probability. In conference rooms, the Unoccupied $\rightarrow$ Occupied state transition probability was the highest after the employees arrive at the office in the morning, and when they begin their duties in the afternoon; the Occupied $\rightarrow$ Unoccupied state transition probability gradually increased with the working time.

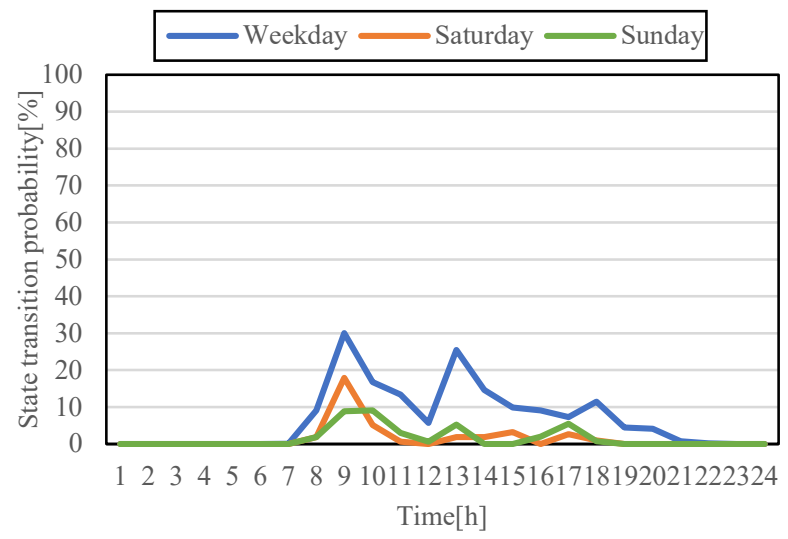


Figure 16: Unoccupied $\rightarrow$ Occupied state transition probability (Office-Conference room)

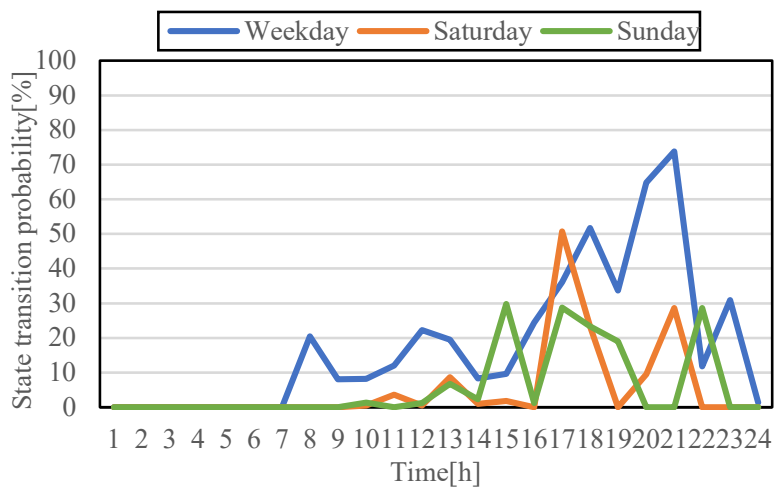

Figure 17: Occupied $\rightarrow$ Unoccupied state transition probability (Office - Conference room)

In Case 2, the air conditioner was assumed to be operating between 11 AM to 4 PM on weekdays, 9 AM to 4 PM on Saturdays, a nd not in use all day on Sundays.

First, we conducted a comparison of the indoor units. The duration curves in Figure 18 show that in some properties, the actual air-conditioning frequency was considerably low, and Case 2 vastly overestimated these durations. Further, the results of Case 3showed increased accuracy as in the case of the hotels, and were the closest to the results of Case 1. Table 4 shows that in Case 2, the operation time of the indoor unit and the cumulative period $h$ eat load were overestimated for both room types, and the peak load was underestimated.

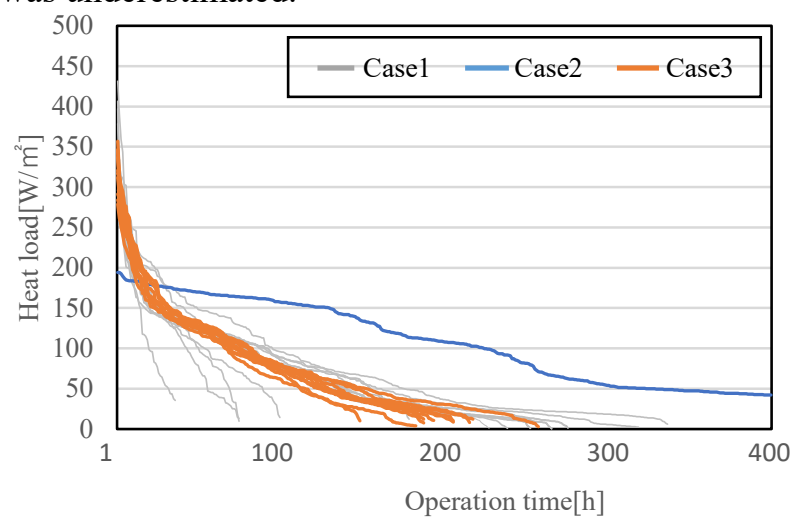

Figure 18: Indoor unit duration curve

(Office-Conference room)

Next, we compared the results of indoor units. Figure 19 shows that though the operation time of the indoor unit in Case 2 does not differ significantly from that of Case 1, the load is overestimated since all the indoor units are assumed to be operating at the same time. Further, as with hotels, the accuracy of the results improved in Case 3. The accuracy was high around the peak value in Case 2, but poor elsewhere. Table 5 shows that the cumulative period heat load of outdoor units was overestimated in Case 2 for both the room types.

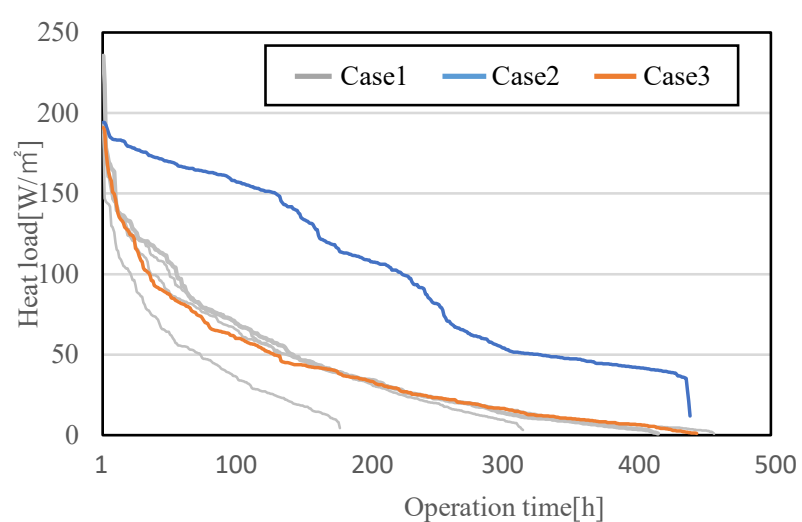

Figure 19: Outdoor unit duration curve

(Office-Conference room)

Table 4: Indoor unit running time and median heat load

\begin{tabular}{|c|c|c|c|c|c|}
\hline \multicolumn{6}{|c|}{ Hotel - Guest room } \\
\hline & $\begin{array}{c}\text { Operation time } \\
{[\mathrm{h}]}\end{array}$ & $\begin{array}{c}\text { Peak } \\
{\left[\mathrm{W} / \mathrm{m}^{2}\right]}\end{array}$ & $\begin{array}{l}\text { Top1\% } \\
{\left[\mathrm{W} / \mathrm{m}^{2}\right]}\end{array}$ & $\begin{array}{l}\text { Top5\% } \\
{\left[\mathrm{W} / \mathrm{m}^{2}\right]}\end{array}$ & $\begin{array}{c}\text { Period load } \\
{\left[\mathrm{kWh} / \mathrm{m}^{2}\right]}\end{array}$ \\
\hline Case 1 & 764 & 239.8 & 165.5 & 71.6 & 28.5 \\
\hline Case2 & 897 & 97.0 & 97.0 & 74.5 & 34.3 \\
\hline Case3 & 522 & 247.6 & 207.4 & 135.5 & 26.0 \\
\hline \multicolumn{6}{|c|}{ Office - Conference room } \\
\hline & $\begin{array}{c}\text { Operation time } \\
{[\mathrm{h}]}\end{array}$ & $\begin{array}{c}\text { Peak } \\
{\left[\mathrm{W} / \mathrm{m}^{2}\right]}\end{array}$ & $\begin{array}{l}\text { Top1\% } \\
{\left[\mathrm{W} / \mathrm{m}^{2}\right]}\end{array}$ & $\begin{array}{l}\text { Top5\% } \\
{\left[\mathrm{W} / \mathrm{m}^{2}\right]}\end{array}$ & $\begin{array}{c}\text { Period load } \\
{\left[\mathrm{kWh} / \mathrm{m}^{2}\right]}\end{array}$ \\
\hline Case 1 & 246 & 319.3 & 266.4 & 184.0 & 18.7 \\
\hline Case2 & 440 & 194.2 & 187.1 & 177.4 & 44.8 \\
\hline Case3 & 200 & 318.6 & 287.9 & 212.6 & 17.9 \\
\hline
\end{tabular}

Table 5: Outdoor unit running time and median heat load

\begin{tabular}{|c|c|c|c|c|c|}
\hline \multicolumn{7}{|c|}{ Hotel - Guest room } \\
\hline & $\begin{array}{c}\text { Operation time } \\
{[\mathbf{h}]}\end{array}$ & $\begin{array}{c}\text { Peak } \\
{\left[\mathbf{W} / \mathbf{m}^{2}\right]}\end{array}$ & $\begin{array}{c}\text { Top1 \% } \\
{\left[\mathbf{W} / \mathbf{m}^{2}\right]}\end{array}$ & $\begin{array}{c}\text { Top5\% } \\
{\left[\mathbf{W} / \mathbf{m}^{2}\right]}\end{array}$ & $\begin{array}{c}\text { Period load } \\
{\left[\mathbf{k W h} / \mathbf{m}^{2}\right]}\end{array}$ \\
\hline Case1 & 1386 & 85.4 & 62.3 & 48.1 & 26.6 \\
\hline Case2 & 898 & 97.1 & 83.7 & 64.3 & 34.3 \\
\hline Case3 & 1421 & 90.1 & 63.4 & 47.1 & 26.1 \\
\hline \multicolumn{7}{|c|}{ Office - Conference room } \\
\hline & $\begin{array}{c}\text { Operation time } \\
{[\mathbf{h}]}\end{array}$ & $\begin{array}{c}\text { Peak } \\
{\left[\mathbf{W} / \mathbf{m}^{2}\right]}\end{array}$ & $\begin{array}{c}\text { Top1\% } \\
{\left[\mathbf{W} / \mathbf{m}^{2}\right]}\end{array}$ & $\begin{array}{c}\mathbf{T} \\
{\left[\mathbf{W} / \mathbf{m}^{2}\right]}\end{array}$ & $\begin{array}{c}\text { Period load } \\
{\left[\mathbf{k W h} / \mathbf{m}^{2}\right]}\end{array}$ \\
\hline Case1 & 416 & 194.0 & 163.6 & 123.7 & 18.9 \\
\hline Case2 & 438 & 194.2 & 187.1 & 177.4 & 44.8 \\
\hline Case3 & 445 & 191.0 & 162.8 & 115.9 & 17.7 \\
\hline
\end{tabular}

\section{Conclusion}

In this study, we investigated split individual airconditioning systems, which can be operated separately in each room, that are installed in rooms that are not regularly used, such as hotel guest rooms and office conference rooms. A field study of the air-conditioning operation in such rooms showed that there was a variation in the start time and durations between the conventionally used design schedules and the actual schedules. Thus, we tested a room-use model employing the state transition probability of room occupancy to determine the start/stop of air-conditioning units in randomly occupied rooms.

When split individual air-conditioning systems are installed, if a fixed schedule is assigned to all the rooms, the maximum heat load of the indoor 
units tends to be underestimated, and that of the outdoor units tends to be overestimated. Additionally, the cumulative period heat load in the summer tends to be overestimated for outdoor units. On the other hand, a maximum heat load and cumulative period heat load that are closer to the actual conditions can be obtained by stochastically determining the start/stop of air conditioning in all the rooms.

The room-use model proposed in this research is effective in calculating the heat load of rooms that are not regularly used. It is possible to apply this model to calculate the primary energy and to select the capacity of air-conditioning units.

However, more research is required to investigate different methods to consider the variation in air-conditioning operations of each room and to modify the model to analyze the yearround room usage.

\section{References}

J. Page et al.(2008). A generalised stochastic model for the simulation of occupant presence, Energy and Buildings 40,pp. 83-98

K.U. Ahn et al.(2016). Different Occupant Modeling Approaches for Building Energy Prediction, Energy Procedia 88,pp. 721-724

J. Tanimoto et al. (2009). A comprehensive method for utility demand estimation with consideration for the diversity of daily schedules of residents 